\title{
Evaluation of low back pain and assessment of lumbar corsets with and without back supports
}

\author{
R. MILLION, ${ }^{1}$ K. HAAVIK NILSEN, ${ }^{2}$ M. I. V. JAYSON, ${ }^{1}$ \\ AND R. D. BAKER ${ }^{3}$
}

From the ${ }^{1}$ Rheumatic Diseases Centre, University of Manchester, Hope Hospital; the ${ }^{3}$ Computing Laboratory, University of Salford; and Betanien Hospital, 3700 Skien, Norway

SUMmARY A method is described for evaluating the progress of patients with back pain. Various symptoms were scored on analogue scales and spinal motion was measured by various techniques. These data were integrated to make subjective and objective indices respectively. Reasonable reproducibility of the measurements was obtained. This technique was used to elucidate the role of the lumbar support in surgical corsets in relief of back pain. Sufferers from back pain were randomly allocated to corsets with and without lumbar supports. There was significant improvement in those with a support compared with those without. On the other hand objective changes measured with the corset removed did not differ between the 2 groups. This study indicates that the spinal support in a lumbosacral corset makes a significant contribution towards the relief of symptoms.

Low back pain is a major cause of disability and is the commonest of rheumatological complaints. ${ }^{1}$ Objective data on the values of various forms of treatment are largely lacking, partly because of the difficulties of defining the underlying problem in individual subjects and also because of difficulties in evaluating progress in any individual. In this study we have employed a number of subjective and objective criteria for following the disease course and examined their reproducibility. We have developed a method for combining these assessments to form overall subjective and objective criteria respectively.

These criteria have been used to evaluate the mechanisms of benefit provided by lumbar corsets. The relief of symptoms while wearing a lumbar corset could be related to the spinal support restricting spinal movements and making the subject sit and stand in a better posture, or alternatively to a tight corset increasing the intra-abdominal pressure, so allowing a substantial proportion of the body load to be transmitted through the abdomen rather than through the spine. Advantage was taken of a new design of lumbar corset, in which spinal support is provided by a removable heat-mouldable plastic

Accepted for publication 15 December 1980.

Correspondence to Professor M. I. V. Jayson, Rheumatic Diseases Centre, Hope Hospital, Eccles Old Road, Salford M6 8HD. insert, to examine the contribution of the lumbar support to the relief of symptoms.

\section{Patients and methods}

Suitable patients attending the Back Pain Clinic in the Rheumatic Diseases Centre were invited to participate in the study. The patients were of either sex, over 18 years of age, had suffered from chronic back pain for at least 6 months, and had not responded satisfactorily to any form of treatment. Patients who had previously tried some form of spinal support were excluded. Screening investigations included blood sedimentation rate, full blood count, a biochemical profile, routine examination of urine, and plain radiographic examination of the lumbosacral spine. Patients were excluded if any abnormality other than lumbar spondylosis was found.

The patients were randomly allocated a lumbar corset with or without a spinal support. The corset, manufactured by Johnson and Johnson Ltd consists of a wide wrap-over body belt in various sizes and fastened by a belt. In the back of the corset is a large pocket designed to hold the plastic insert (Fig. 1) This insert is made of Orthoplast, a new synthetic material which is rigid at and below body temperature but is readily mouldable when heated to $72-75^{\circ} \mathrm{C}$. By 


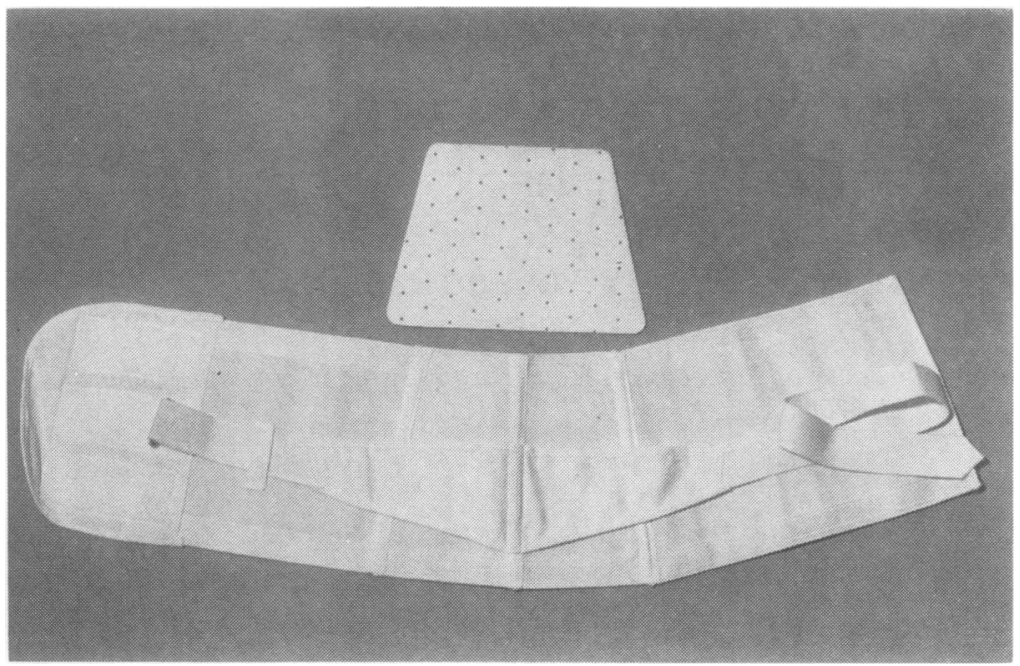

Fig. 1 The lumbosacral corset with the heat-mouldable plastic spinal support.

heating the support to this temperature it is possible to mould the insert to the patient's back in an upright position, and this shape is retained thereafter.

The patients were not told whether the plastic insert was thought to be of importance. They were asked to wear the corset during the day and also given instruction on appropriate methods of bending, lifting, and care of the back.

Assessments were made on entry to the trial and at 4 weeks and 8 weeks of corset use. Each assessment was duplicated so as to allow a measure of the reproducibility of the findings. The subjective assessments were a series of questions directed at establishing the severity of symptoms and how much they interfered with normal activities. The questions are listed in Table 1. A visual analogue scale was used. Each question was answered by the patient's marking where he felt his own symptoms lay on a straight line whose extremes represented the extreme answers to the questions. By measuring the distance of the patient's mark along this line we obtained an index of severity of symptoms for that particular subject which could be compared with subsequent recordings for that individual.

Objective measurements of straight leg raising and of spinal movements were obtained. Straight leg raising was measured by placing a spirit-level goniometer on the extended lower leg and measuring the angular movement during the procedure. Extension, forward flexion, and lateral flexion to the right and left were separately measured with the spirit level goniometer ${ }^{2}$ and a tape measure by methods similar to those described by Moll and Wright. ${ }^{3}$ The objective measurements are listed in Table 2.
Table 1 Subjective variables asked on back pain questionnaire for visual analogue assessment

1. Do you have any pain in the back? How severe is it? (No pain-intolerable)

2. Do you have any pain in the night? How severe is it? (No pain-intolerable)

3. Is there anything that you do or are there any circumstances in your life style which makes your pain worse? If so, how stressful has this to be to give you pain? (Very stressful-not stressful at all).

4. Do you get relief from pain killers? (Complete relief-no relief)

5. Do you have any stiffness in the back? (No stiffnessintolerable stiffness)

6. Does your back pain interfere with your freedom to walk? (Complete freedom to walk-completely unable to walk because of pain)

7. Do you have discomfort when walking? (None at allintolerable)

8. Does your pain interfere with your ability to stand still? (Stand still for a long time, that is an hour-not able to stand still at all)

9. Does your pain prevent you from turning and twisting? (Complete freedom to twist-completely incapable of twisting)

10. Does your back pain allow you to sit on an upright hard chair? (Complete freedom to sit on a hard chair-so much pain that cannot sit on such a chair at all)

11. Does your back pain prevent you from sitting in a soft armchair? (Complete comfort-such discomfort that you cannot sit in a soft chair at all)

12. Do you have back pain when lying down in bed? (Complete comfort-no comfort at all)

13. What is your overall handicap in your complete life style because of back pain? (Completely free to perform any task-totally handicapped)

14. To what extent does your pain interfere with your work? (No interference at all-totally incapable of work)

15. To what extent does your work have to be modified so that you are able to do your job? (No adjustment to work-so much adjustment that have had to change your job) 
Table 2 Objective assessments

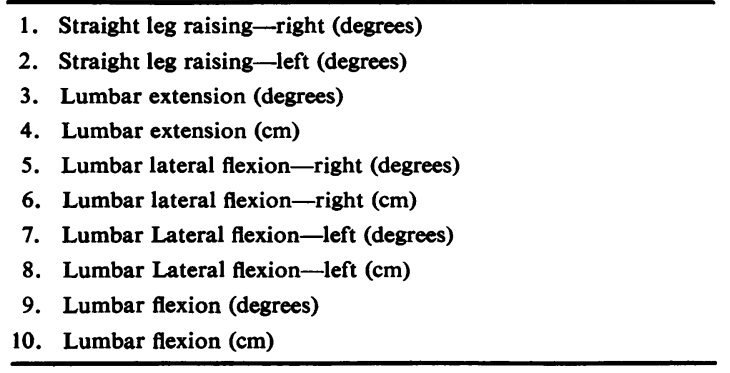

Statistical analyses were undertaken for each type of assessment separately and in combination, and comparisons were drawn of the changes in the assessment results at 4 weeks and 8 weeks.

\section{Results}

Nineteen patients entered the study. Nine were allocated to the corset with the support and $\mathbf{1 0}$ without. Both groups were of comparable age (47.1 years), but those without were more commonly female than those with the support (with support $M: F 5: 4$, without support 1:9).

Table 3 shows the correlation coefficients between the duplicate measurements for each variable. It can be seen that there was a high degree of repro-

Table 3 Correlation coefficients between replicate assessments

\begin{tabular}{ll}
\hline Subjective assessments & \\
1 & 0.855 \\
2 & 0.895 \\
3 & 0.853 \\
4 & 0.883 \\
5 & 0.869 \\
6 & 0.917 \\
7 & 0.916 \\
8 & 0.921 \\
9 & 0.900 \\
10 & 0.917 \\
11 & 0.937 \\
12 & 0.907 \\
13 & 0.895 \\
14 & 0.847 \\
15 & 0.882 \\
Subjective index & 0.966 \\
Objective assessments & \\
1 & 0.971 \\
2 & 0.971 \\
3 & 0.946 \\
4 & 0.788 \\
5 & 0.919 \\
6 & 0.912 \\
7 & 0.858 \\
8 & 0.912 \\
9 & 0.842 \\
10 & 0.911 \\
Objective index & 0.986 \\
\hline
\end{tabular}

ducibility. The means of each pair of readings were used in subsequent analyses.

In the 2 treatment groups the changes in scores between months 1 and 2 and between 1 and 3 were recorded and the probabilities that such changes could occur by chance were determined by the Wilcoxon signed rank test. The magnitudes of the changes occurring with the 2 corset types at 4 weeks and 8 weeks were compared by the Mann-Whitney $U$ test (Tables 4 and 5).

With respect to the subjective criteria (Table 4), in the patients wearing a corset with a support (group 1) there were improvements in pain at night and in bed (questions 2 and 12), interference with lifestyle and work (questions 13, 14, and 15), and discomfort when walking (question 7). In those without the support (group 2) improvement was noted in pain only when lying down in bed (question 12). Significantly greater improvements were noted in favour of those with a spinal support (group 1) in ability to turn and twist (question 9), pain in bed (question 12), and interference with work (question 14).

With regard to objective measurements (Table 5), in those with a spinal support (group 1) significant improvements in extension were shown with the goniometer (measurement 3), and flexion (measurements 9 and 10). In those without the support there were improvements in straight leg raising (measurements 1 and 2) and extension (measurement 3). There were no differences in the changes between the 2 groups.

In order to obtain overall measurements of progress the subjective variables and the objective

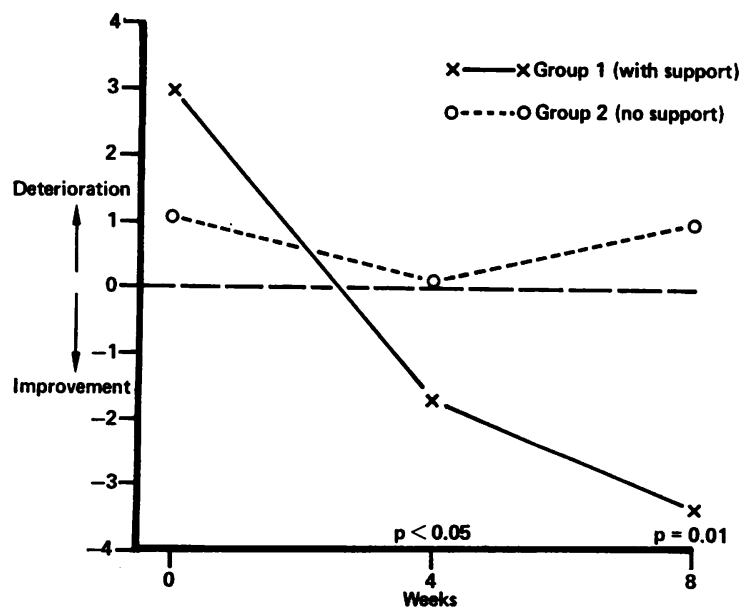

Fig. 2 Alterations in subjective index. The improvement in those with the support is significantly greater than in those without the support at 4 and 8 weeks. 
measurements were combined to form subjective and objective indices respectively. These were taken by adjusting the means and magnitudes of change for each variable to make them comparable and combining them.
The global subjective index for all patients 0 improved over the study period. However, analysis? showed highly significant improvement in the patients $\vec{F}$ with the spinal support (group 1), but no change in those with the corset without the support (group 2).

Table 4 Variation of subjective variable means during treatment

\begin{tabular}{|c|c|c|c|c|c|c|c|c|c|c|c|}
\hline Variable & $\begin{array}{l}\text { Corset } \\
\text { Group }\end{array}$ & 1st mean & 2nd mean & $3 r d$ mean & $2 n d-1 s t$ & Prob \% & $3 r d-1 s t$ & Prob \% & $\begin{array}{l}\text { Group } 1 / 2 \\
\text { Prob 2-1\% }\end{array}$ & $\begin{array}{l}\text { Group } \\
\text { Prob } 3\end{array}$ & $\begin{array}{l}1 / 2 \\
-1 \%\end{array}$ \\
\hline 1 & $\begin{array}{l}1 \\
2\end{array}$ & $\begin{array}{l}5 \cdot 3 \\
5 \cdot 2\end{array}$ & $\begin{array}{l}5 \cdot 0 \\
4 \cdot 2\end{array}$ & $\begin{array}{l}3 \cdot 3 \\
4 \cdot 1\end{array}$ & $\begin{array}{l}-0.3 \\
-1.0\end{array}$ & $\begin{array}{l}20 \\
57\end{array}$ & $\begin{array}{l}-2 \cdot 0 \\
-1 \cdot 1\end{array}$ & $\begin{array}{l}13 \\
26\end{array}$ & 56 & 60 & \\
\hline 2 & $\begin{array}{l}1 \\
2\end{array}$ & $\begin{array}{l}5 \cdot 3 \\
4 \cdot 1\end{array}$ & $\begin{array}{l}3 \cdot 2 \\
3 \cdot 4\end{array}$ & $\begin{array}{l}2 \cdot 8 \\
4 \cdot 2\end{array}$ & $\begin{array}{l}-2 \cdot 1 \\
-0.7\end{array}$ & $\begin{array}{r}17 \\
100\end{array}$ & $\begin{array}{r}-2.5 \\
0.1\end{array}$ & 100 & 42 & 6 & \\
\hline 3 & $\begin{array}{l}1 \\
2\end{array}$ & $\begin{array}{l}6 \cdot 6 \\
5 \cdot 4\end{array}$ & $\begin{array}{l}5 \cdot 8 \\
5 \cdot 6\end{array}$ & $\begin{array}{l}5 \cdot 3 \\
6 \cdot 3\end{array}$ & $\begin{array}{r}-0.8 \\
0.2\end{array}$ & $\begin{array}{l}75 \\
24\end{array}$ & $\begin{array}{r}-1.3 \\
0.9\end{array}$ & $\begin{array}{l}40 \\
87\end{array}$ & 44 & 91 & \\
\hline 4 & $\begin{array}{l}1 \\
2\end{array}$ & $\begin{array}{l}5 \cdot 8 \\
5 \cdot 7\end{array}$ & $\begin{array}{l}4 \cdot 8 \\
5 \cdot 3\end{array}$ & $\begin{array}{l}3 \cdot 4 \\
6 \cdot 4\end{array}$ & $\begin{array}{l}-1.0 \\
-0.4\end{array}$ & $\begin{array}{l}89 \\
60\end{array}$ & $\begin{array}{r}-2.4 \\
0.7\end{array}$ & $\begin{array}{l}12 \\
69\end{array}$ & 75 & 10 & \\
\hline 5 & $\begin{array}{l}1 \\
2\end{array}$ & $\begin{array}{l}3 \cdot 6 \\
4 \cdot 7\end{array}$ & $\begin{array}{l}2 \cdot 5 \\
3 \cdot 8\end{array}$ & $\begin{array}{l}2 \cdot 3 \\
3 \cdot 8\end{array}$ & $\begin{array}{l}-1 \cdot 1 \\
-0.9\end{array}$ & $\begin{array}{l}12 \\
18\end{array}$ & $\begin{array}{l}-1 \cdot 3 \\
-0.9\end{array}$ & $\begin{array}{l}17 \\
13\end{array}$ & 28 & 55 & \\
\hline 6 & $\begin{array}{l}1 \\
2\end{array}$ & $\begin{array}{l}4 \cdot 0 \\
3 \cdot 3\end{array}$ & $\begin{array}{l}2 \cdot 5 \\
2 \cdot 7\end{array}$ & $\begin{array}{l}2 \cdot 9 \\
3 \cdot 1\end{array}$ & $\begin{array}{l}-1.5 \\
-0.6\end{array}$ & $\begin{array}{l}34 \\
57\end{array}$ & $\begin{array}{l}-1 \cdot 1 \\
-0 \cdot 2\end{array}$ & $\begin{array}{l}13 \\
46\end{array}$ & 42 & 14 & \\
\hline 7 & $\begin{array}{l}1 \\
2\end{array}$ & $\begin{array}{l}4 \cdot 2 \\
4 \cdot 0\end{array}$ & $\begin{array}{l}3 \cdot 2 \\
3 \cdot 1\end{array}$ & $\begin{array}{l}2 \cdot 7 \\
3 \cdot 6\end{array}$ & $\begin{array}{l}-1 \cdot 0 \\
-0.9\end{array}$ & $\begin{array}{l}4 \cdot 5 \\
48\end{array}$ & $\begin{array}{l}-1 \cdot 5 \\
-0.4\end{array}$ & $\begin{array}{r}6 \\
33\end{array}$ & 16 & 11 & \\
\hline 8 & $\begin{array}{l}1 \\
2\end{array}$ & $\begin{array}{l}3 \cdot 9 \\
5 \cdot 1\end{array}$ & $\begin{array}{l}2 \cdot 9 \\
3 \cdot 6\end{array}$ & $\begin{array}{l}2 \cdot 2 \\
4 \cdot 5\end{array}$ & $\begin{array}{l}-1 \cdot 0 \\
-1 \cdot 5\end{array}$ & $\begin{array}{l}7 \cdot 5 \\
48\end{array}$ & $\begin{array}{l}-1.7 \\
-0.6\end{array}$ & $\begin{array}{r}9 \\
24\end{array}$ & 42 & 40 & \\
\hline 9 & $\begin{array}{l}1 \\
2\end{array}$ & $\begin{array}{l}4 \cdot 4 \\
5 \cdot 1\end{array}$ & $\begin{array}{l}2 \cdot 7 \\
4 \cdot 7\end{array}$ & $\begin{array}{l}3.7 \\
8 \cdot 0\end{array}$ & $\begin{array}{l}-1.7 \\
-0.4\end{array}$ & $\begin{array}{l}7 \cdot 5 \\
40\end{array}$ & $\begin{array}{r}-0.7 \\
2.9\end{array}$ & $\begin{array}{l}13 \\
78\end{array}$ & 5 & 67 & \\
\hline 10 & $\begin{array}{l}1 \\
2\end{array}$ & $\begin{array}{l}3 \cdot 9 \\
3 \cdot 0\end{array}$ & $\begin{array}{l}3 \cdot 8 \\
3 \cdot 5\end{array}$ & $\begin{array}{l}2 \cdot 7 \\
3 \cdot 3\end{array}$ & $\begin{array}{r}-0.1 \\
0.5\end{array}$ & $\begin{array}{l}39 \\
23\end{array}$ & $\begin{array}{r}-1 \cdot 2 \\
0 \cdot 3\end{array}$ & $\begin{array}{r}9 \\
67\end{array}$ & 49 & 17 & \\
\hline 11 & $\begin{array}{l}1 \\
2\end{array}$ & $\begin{array}{l}4 \cdot 2 \\
5 \cdot 4\end{array}$ & $\begin{array}{l}3 \cdot 7 \\
3 \cdot 5\end{array}$ & $\begin{array}{l}4 \cdot 5 \\
4 \cdot 5\end{array}$ & $\begin{array}{l}-0.5 \\
-1.9\end{array}$ & $\begin{array}{l}75 \\
89\end{array}$ & $\begin{array}{r}0.3 \\
-0.9\end{array}$ & $\begin{array}{l}60 \\
26\end{array}$ & 80 & 45 & 응 \\
\hline 12 & $\begin{array}{l}1 \\
2\end{array}$ & $\begin{array}{l}5 \cdot 1 \\
5 \cdot 2\end{array}$ & $\begin{array}{l}3 \cdot 5 \\
3 \cdot 5\end{array}$ & $\begin{array}{l}1 \cdot 8 \\
4 \cdot 3\end{array}$ & $\begin{array}{l}-1.6 \\
-1.7\end{array}$ & $\begin{array}{l}4 \cdot 5 \\
40\end{array}$ & $\begin{array}{l}-3 \cdot 3 \\
-0 \cdot 9\end{array}$ & $\begin{array}{l}3 \\
3 \cdot 5\end{array}$ & 2 & 7 & 흐. \\
\hline 13 & $\begin{array}{l}1 \\
2\end{array}$ & $\begin{array}{l}5 \cdot 0 \\
3 \cdot 4\end{array}$ & $\begin{array}{l}3 \cdot 4 \\
3 \cdot 0\end{array}$ & $\begin{array}{l}3 \cdot 5 \\
3 \cdot 6\end{array}$ & $\begin{array}{l}-1.6 \\
-0.4\end{array}$ & $\begin{array}{l}14 \\
33\end{array}$ & $\begin{array}{r}-1 \cdot 5 \\
0 \cdot 2\end{array}$ & $\begin{array}{l}4 \cdot 5 \\
86\end{array}$ & 13 & 10 & \\
\hline 14 & $\begin{array}{l}1 \\
2\end{array}$ & $\begin{array}{l}5 \cdot 1 \\
4 \cdot 0\end{array}$ & $\begin{array}{l}3 \cdot 4 \\
3 \cdot 2\end{array}$ & $\begin{array}{l}3 \cdot 8 \\
3 \cdot 7\end{array}$ & $\begin{array}{l}-1 \cdot 7 \\
-0.8\end{array}$ & $\begin{array}{l}4 \cdot 5 \\
89\end{array}$ & $\begin{array}{l}-1 \cdot 3 \\
-0 \cdot 3\end{array}$ & $\begin{array}{l}12 \\
36\end{array}$ & 1 & 40 & \\
\hline 15 & $\begin{array}{l}1 \\
2\end{array}$ & $\begin{array}{l}4 \cdot 2 \\
4 \cdot 9\end{array}$ & $\begin{array}{l}3 \cdot 7 \\
2 \cdot 6\end{array}$ & $\begin{array}{l}2 \cdot 7 \\
3 \cdot 6\end{array}$ & $\begin{array}{l}-0 \cdot 5 \\
-2 \cdot 3\end{array}$ & $\begin{array}{l}4 \cdot 5 \\
16\end{array}$ & $\begin{array}{l}-1 \cdot 5 \\
-1 \cdot 3\end{array}$ & $\begin{array}{l}13 \\
13\end{array}$ & 90 & 95 & \\
\hline Subjective index & $\begin{array}{l}1 \\
2\end{array}$ & $\begin{array}{l}2.99 \\
1.08\end{array}$ & $\begin{array}{r}-1 \cdot 68 \\
0.11\end{array}$ & $\begin{array}{r}-3.39 \\
0.97\end{array}$ & $\begin{array}{l}-4.67 \\
-0.97\end{array}$ & $\begin{array}{l}0 \cdot 1 \\
30\end{array}$ & $\begin{array}{l}-6 \cdot 38 \\
-0 \cdot 11\end{array}$ & $\begin{array}{l}0 \cdot 1 \\
93\end{array}$ & $4 \cdot 6$ & 1 & \\
\hline Subjective index & both & $1 \cdot 98$ & -0.74 & $-1 \cdot 12$ & $-2 \cdot 72$ & $0 \cdot 3$ & $-3 \cdot 10$ & 2 & & & \\
\hline
\end{tabular}

Table 5 Variation of objective variable means during treatment

\begin{tabular}{|c|c|c|c|c|c|c|c|c|c|c|}
\hline Variable & $\begin{array}{l}\text { Corset } \\
\text { Group }\end{array}$ & Ist mean & $2 n d$ mean & $3 r d$ mean & $2 n d-1 s t$ & Prob \% & $3 r d-1 s t$ & Prob \% & $\begin{array}{l}\text { Group } 1 / 2 \\
\text { Prob 2-1\% }\end{array}$ & $\begin{array}{l}\text { Group } 1 / 2 \\
\text { Prob } 3-1 \%\end{array}$ \\
\hline \multirow[t]{2}{*}{1} & 1 & $60 \cdot 2$ & $65 \cdot 8$ & $64 \cdot 8$ & $5 \cdot 6$ & 46 & $4 \cdot 6$ & 20 & 19 & 48 \\
\hline & 2 & $57 \cdot 6$ & $65 \cdot 1$ & $63 \cdot 9$ & $7 \cdot 5$ & 3 & $6 \cdot 3$ & $2 \cdot 8$ & & \\
\hline \multirow[t]{2}{*}{2} & 1 & $57 \cdot 9$ & $59 \cdot 8$ & $60 \cdot 1$ & $1 \cdot 9$ & 8 & $2 \cdot 2$ & 50 & 89 & 54 \\
\hline & 2 & 60.0 & 63.9 & $63 \cdot 8$ & 3.9 & $4 \cdot 5$ & $3 \cdot 8$ & $4 \cdot 3$ & & \\
\hline \multirow[t]{2}{*}{3} & 1 & $7 \cdot 7$ & $8 \cdot 7$ & $9 \cdot 8$ & 1.0 & 83 & $2 \cdot 1$ & $4 \cdot 6$ & 69 & 96 \\
\hline & 2 & $8 \cdot 9$ & 9.9 & $10 \cdot 8$ & 1.0 & 38 & $1 \cdot 9$ & $2 \cdot 7$ & & \\
\hline \multirow[t]{2}{*}{4} & 1 & $13 \cdot 8$ & $12 \cdot 9$ & $13 \cdot 7$ & -0.9 & 36 & -0.1 & 67 & 31 & 96 \\
\hline & 2 & $13 \cdot 8$ & $13 \cdot 8$ & $13 \cdot 7$ & 0.0 & 95 & $-0 \cdot 1$ & 60 & & \\
\hline \multirow[t]{2}{*}{5} & 1 & $16 \cdot 1$ & 15.4 & $16 \cdot 8$ & -0.7 & 86 & 0.7 & 77 & 75 & 66 \\
\hline & 2 & $17 \cdot 7$ & $15 \cdot 3$ & $17 \cdot 5$ & $-2 \cdot 4$ & 51 & -0.2 & 68 & & \\
\hline \multirow[t]{2}{*}{6} & 1 & $50 \cdot 3$ & $47 \cdot 9$ & $50 \cdot 8$ & -2.4 & 78 & 0.5 & 61 & 59 & 18 \\
\hline & 2 & $48 \cdot 1$ & $48 \cdot 4$ & $46 \cdot 9$ & 0.3 & 23 & $-1 \cdot 2$ & 14 & & \\
\hline \multirow[t]{2}{*}{7} & 1 & $16 \cdot 8$ & $15 \cdot 0$ & $17 \cdot 4$ & $-1 \cdot 8$ & 57 & 0.6 & 77 & 78 & 90 \\
\hline & 2 & $16 \cdot 8$ & $14 \cdot 3$ & 15.4 & $-2 \cdot 5$ & 32 & -1.4 & 51 & & \\
\hline \multirow[t]{2}{*}{8} & 1 & $51 \cdot 3$ & $48 \cdot 9$ & 51.0 & $-2 \cdot 4$ & 57 & -0.3 & 40 & 72 & 50 \\
\hline & 2 & $48 \cdot 7$ & $48 \cdot 2$ & $47 \cdot 7$ & -0.5 & 87 & $-1 \cdot 0$ & 26 & & \\
\hline \multirow[t]{2}{*}{9} & 1 & $11 \cdot 3$ & $12 \cdot 7$ & 15.4 & 1.4 & 26 & $4 \cdot 1$ & $1 \cdot 1$ & 82 & 7 \\
\hline & 2 & $14 \cdot 2$ & $16 \cdot 1$ & $16 \cdot 7$ & 1.9 & 44 & $2 \cdot 5$ & 51 & & \\
\hline \multirow[t]{2}{*}{10} & 1 & $17 \cdot 1$ & $16 \cdot 2$ & $17 \cdot 5$ & -0.9 & 89 & 0.4 & $3 \cdot 5$ & 37 & 45 \\
\hline & 2 & $17 \cdot 0$ & $17 \cdot 0$ & $17 \cdot 2$ & 0.0 & 21 & $-0 \cdot 2$ & 44 & & \\
\hline Objective index & $\begin{array}{l}1 \\
2\end{array}$ & $\begin{array}{r}1.37 \\
-0.06\end{array}$ & $\begin{array}{r}0.39 \\
-0.09\end{array}$ & $\begin{array}{l}-0.69 \\
-1.20\end{array}$ & $\begin{array}{l}-0.98 \\
-0.03\end{array}$ & $\begin{array}{l}25 \\
95\end{array}$ & $\begin{array}{l}-2 \cdot 06 \\
-1 \cdot 14\end{array}$ & $\begin{array}{l}10 \\
9 \cdot 5\end{array}$ & 84 & 71 \\
\hline Objective index & both & 0.68 & -0.07 & -0.41 & -0.75 & 58 & -1.09 & 1 & & \\
\hline
\end{tabular}




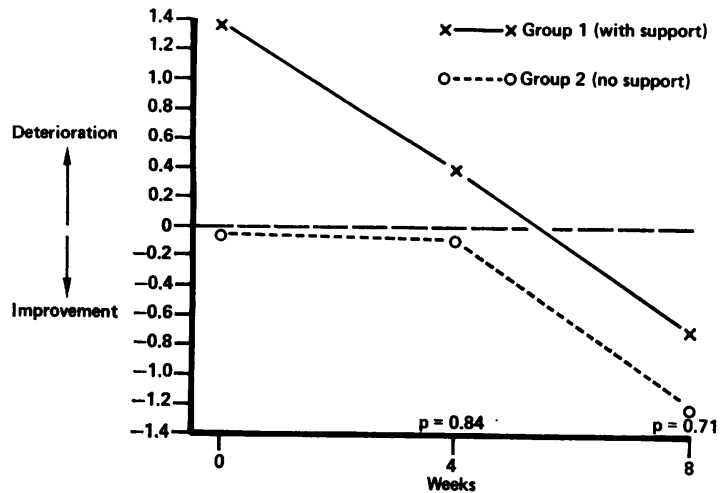

Fig. 3 Alterations in objective index. The improvements in the objective index did not differ between the 2 groups.

The differences between the 2 groups were highly significant (Fig. 2). On the other hand the objective index for all patients showed improvement over the study period but with no difference between the groups (Fig. 3).

\section{Discussion}

Despite the magnitude of the problem of back pain there are no generally accepted methods for following the progress of individual patients or for determining the values of various forms of treatment. The reasons lie in the lack of understanding of the fundamental pathogenesis of many back pain syndromes, the overlapping symptomatology between various back problems, the lack of good objective signs of the disease, and the variable course followed by many patients.

In the present study we have identified a number of variables that seem directly relevant to the back pain problem and have shown, using duplicate measures by the same observer, that it is possible to repeat them with a high degree of reproducibility. In the present study these parameters have shown certain trends which often were not statistically significant. However, it was possible to combine them into subjective and objective indices in an attempt to provide more broadly based information about the patients' progress. It is appreciated that there are overlapping features between several of these tests. For example, there are 2 questions relevant to pain in bed and 2 separate tests using different techniques for measuring each spinal movement. Nevertheless these variables all measure slightly different things, and indeed there were some discrepancies between tests with overlapping features. It was therefore felt better to use all the tests in deriving the 2 indices.

In the overall analyses the subjective index was separated from the objective measurements. The severity of the symptoms and their interference with life style are of fundamental concern to the patient. The ranges of spinal motion and straight leg raising are useful objective measures of spinal function but may correlate poorly with the patients' problems. To take an extreme example, the spine in advanced ankylosing spondylitis may be fused and rigid but commonly is symptom-free, and provided there is no other problem the patient may experience little if any disability. For this reason in assessing a symptomatic form of treatment, such as a lumbar corset, the principal emphasis must be on the relief of symptoms rather than on changes in spinal motion.

In this study we have demonstrated significant relief of symptoms by wearing a lumbar corset with a spinal support. On the other hand a similar corset without the support failed to provide any relief. As might be expected, no significant alteration occurred in spinal movements measured when the corset was removed.

There are 2 postulated mechanisms for relief of symptoms by a lumbar corset. The firm lumbar support may restrict motion in various directions and so prevent the patient from undertaking movements that may precipitate pain. There is conflicting information about whether spinal movements are restricted by wearing a lumber corset. ${ }^{45}$ Andersson ${ }^{6}$ has shown the influence of a well designed lumbar support in maintaining the lumbar lordosis and how the optimum position minimises the stresses transmitted by the intervertebral disc. The alternative hypothesis is that the corset acts as an abdominal binder, so raising the intraperitoneal pressure. ${ }^{7}$ During normal heavy lifting one tenses the abdominal muscles and diaphragm, thereby increasing the intra-abdominal pressure. This allows the peritoneal cavity to transmit a substantial proportion of the total body load and thus relieve the spine. This may be compared with the abdominal binder worn by weightlifters to increase their ability to lift heavy weights. It may be that a tight corset will act in a similar fashion by limiting the stress on the spine and therefore the symptoms of back pain.

The present study does not support the concept that symptoms are relieved by the corset acting as an abdominal binder. There was no improvement in the overall subjective index in the patients wearing the corset without a spinal support. On the other hand in the group wearing the corset with the support there was a considerable and significant overall improvement in symptoms. This suggests that the principal mechanism of relief of symptoms by a lumbar corset is the restriction of spinal motion that it imposes. 
We acknowledge with thanks support by Messrs Johnson and Johnson and the use of computing facilities (ICL 1904 S) in the University of Salford.

\section{References}

1 Anderson J A D. Back pain and occupation. In: Jayson M I V, ed. The Lumbar Spine and Back Pain. 2nd ed. London: Pitman Medical, 1980: 57-82.

2 Loebl W T. Measurement of spinal posture and range of spinal movement. Ann Phys Med 1967; 9: 103.

3 Moll, J, Wright V. Measurement of spinal movement. In: Jayson M I V, ed. The Lumbar Spine and Back Pain. 2nd ed. London: Pitman Medical, 1980: 157-83.
4 Norton P L, Brown T. The immobilising efficiency of back braces: their effect on the posture and motion of the lumbo-sacral spine. J Bone Joint Surg 1957; 39A: 111-39.

5 Grew N D. 'Functional' assessment of lumbar spine. In: Oxford Orthopaedic Engineering Centre. Annual Report 1979. 45-53.

6 Andersson B J G. On myoelectric back muscle activity and lumbar disc pressure in sitting postures. Thesis. University of Göteborg, Sweden, 1974.

7 Bartelink D L. The role of abdominal pressure in relieving the pressure on the lumbar intervertebral discs. $J$ Bone Joint Surg 1957; 39B: 718-25. 